\title{
THE SIMULATION ANALYSIS OF HIGH EFFICIENCY LOCOMOTIVE DIESEL ENGINE ELECTRICALLY CONTROLLED FUEL INJECTION SYSTEM
}

\author{
Minghai LI *, Chunlin HOU * and Ang LI ** \\ * Dalian JiaoTong University, LiaoNing Dalian, 116028 China \\ ** Tsinghua University, 100084 China
}

\begin{abstract}
Applied software GT-FUEL to build up the physics and the mathematics model of the $16 \mathrm{~V} 280 \mathrm{ZJ}$ diesel engine' electronics injection system. Ask for the help of solenoid valve to control feeding timing and feeding quantity in order to research on optimization of injection pressure and injection rate curves. In contrast with the experiment of the machine injection system to elaborate the superiority of the electronic control system .It showed that optimizing the fuel injection system by GT-FUEL is doubtlessly practical and theoretically estimable for it could not only cut down the experimental workload but uncover some physical phenomena out of reach for experimental investigations.
\end{abstract}

Key words: Diesel engine, Fuel injection system, Solenoid valve, GT-FUEL

\section{INTRODUCTION}

In recent years, along with the world energy enhancement of crisis and people environmental consciousness, the request to the emission and economy of diesel engine become higher. The modern diesel engine set the following request to the fuel injection system: high injection pressure and injection rate as well as adjustable injection duration. The traditional mechanical fuel injection system is hard to satisfy these harshly request. As a result of t-he rapid development of electronic technology, adoption the electronic control injection system can nimbly control the diesel engine's injection timing and injection quantity. The diesel engine can acquire a group of best match value under each work condition. Simultaneity, the problem of diesel engine' economy and emission may well resolve. The mathematical model of the fuel injection system of electronic has been set up in this paper by software GT-FUEL. And applied the finite volume method to carry on the value solution, profoundly has analyzed the feed timing and feed duration on the diesel engine performance effect.

\section{THE WORK PRINCIPLE OF THE ELECTRONICS INJECTION SYSTEM}

The electronic control fuel injection system mainly include the Electronic Unit Pump, injector, the control system. The Solenoid-controlled valve is the key component, also is the electrically controlled breakthrough key technologies. The work principle of electronics injection: The crank drives the oil pump cam to circumrotate, and impels the roller tappet vertical motion. When the plunger uppers shift, the solenoid valve results in electricity closed, the high and low pressure oil cavity circuit cutoff, the plunger starts to press the oil, produced the high-pressured fuel oil to enter the injector through the high-pressure oil pipe, and after nozzle atomizing gushes in the cylinder. When the solenoid valve loses the electricity

Copyright (C) 2009 by the Japan Society of Mechanical Engineering and open, the high and low pressure oil cavity circuit connect, the fuel oil unloads rapidly, the injector stop sprays. The opening and closing of solenoid valve is controlled by control system, the control system is an interior which has microprocessor's electronic control unit. The electronic control unit examinate engine related parameter through each kind of sensor, under the software control in stores up in advance in the control unit, outputs the suitable operating current to control the opening and closing of solenoid valve. According to the signal of top dead center examined by the sensor to determined the solenoid valve shuts down time and closure duration.

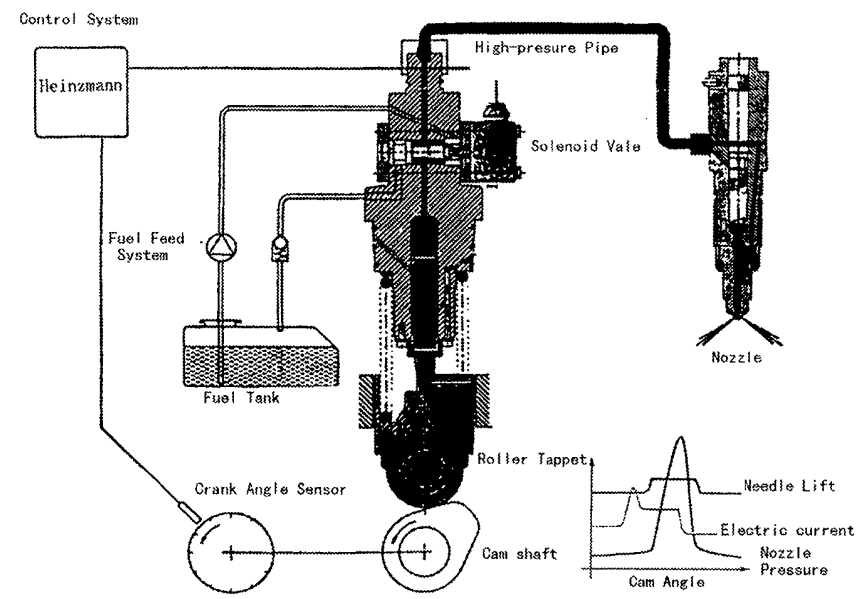

Fig.1 Electronic injection fuel system

\section{THE ESTABLISHMENT OF SIMULATIONAL MODEL}

Draw the mold blocks of crank, camshaft, the injection pump, the solenoid valve, the high-pressure oil pipe, injector stored in GT-FUEL database in the modeling region. After however, to connect them according to shown in Figure 1. The oil injection system's imitation mold can be 
acquired as shown in Figure 2.The mainly construction parameter of various molds block is shown in table 1 .

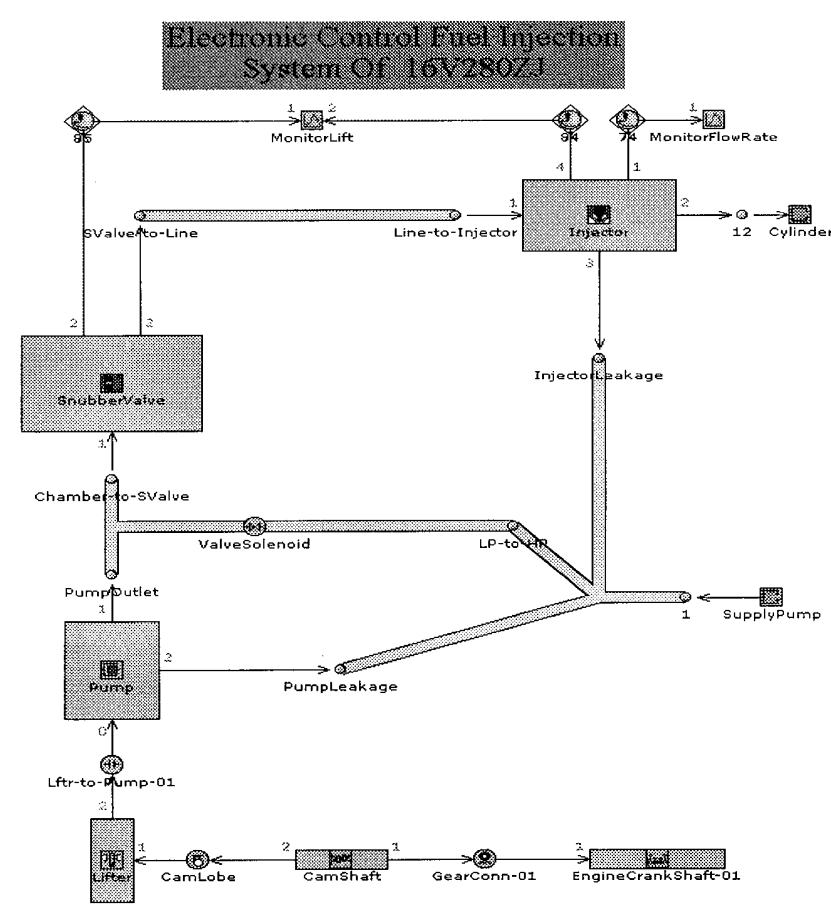

Fig.2 The 16V280ZJ electronic control diesel fuel injection system

Table1 16V280ZJ diesel engine fuel injection system's primary structure parameter

\begin{tabular}{|c|c|c|}
\hline \multirow{4}{*}{$\begin{array}{c}\text { injection } \\
\text { pump }\end{array}$} & plunger Diameter $/ \mathrm{mm}$ & 22 \\
\cline { 2 - 3 } & plunger stroke $/ \mathrm{mm}$ & 20 \\
\cline { 2 - 3 } & plunger Mass $/ \mathrm{g}$ & 1157 \\
\cline { 2 - 3 } $\begin{array}{c}\text { high-pressure } \\
\text { pipe }\end{array}$ & Initial Pump Volume $/ \mathrm{mm}^{3}$ & 8700 \\
\cline { 2 - 3 } & Length $/ \mathrm{mm}$ & 600 \\
\hline \multirow{4}{*}{ injector } & Diameter $/ \mathrm{mm}$ & 2 \\
\cline { 2 - 3 } & $\begin{array}{c}\text { Number of Injector Holes } \times \\
\text { Diameter of Holes } / \mathrm{mm}\end{array}$ & $10 \times 0.45$ \\
\cline { 2 - 3 } & Length of Holes $/ \mathrm{mm}$ & 2 \\
\cline { 2 - 3 } & Feed Hole Diameter $/ \mathrm{mm}$ & 2 \\
\cline { 2 - 3 } & Needle Stem Type & U short -stem \\
\hline
\end{tabular}

\section{THE OPTIMIZATION PLAN OF SIMULATION}

Make use of GT-FUEL optimized module Optimizer to discuss the influence of feed timing to spraying process. Carries on the optimization in Optimizer to the feed timing. When the solenoid valve closure and opening angle separately are $17^{\circ}$ and $10^{\circ}$, it can obtain the superior project. As shown in Table 2.

Table2 Solenoid valve's optimized angle

\begin{tabular}{|l|c|c|}
\hline Solenoid valve & Crank angle $/ \mathrm{deg}$ & valve lift $/ \mathrm{mm}$ \\
\hline Closure angle & -17 & 0 \\
\hline Opening angle & 10 & 1.03 \\
\hline
\end{tabular}

\section{THE RESULT ANALYSIS OF SIMULATION}

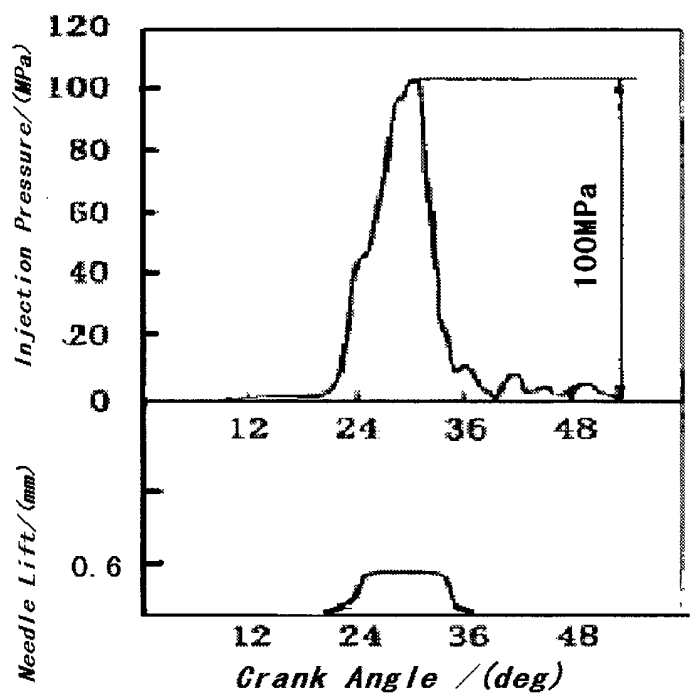

Fig.3 Mechanical 16V280 injection pressure and needle lift curve

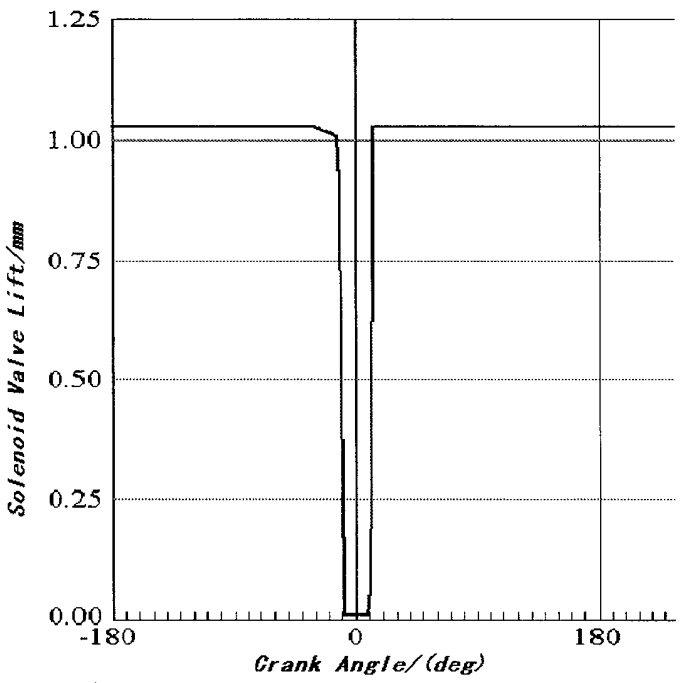

Fig.4 Solenoid valve lift curve

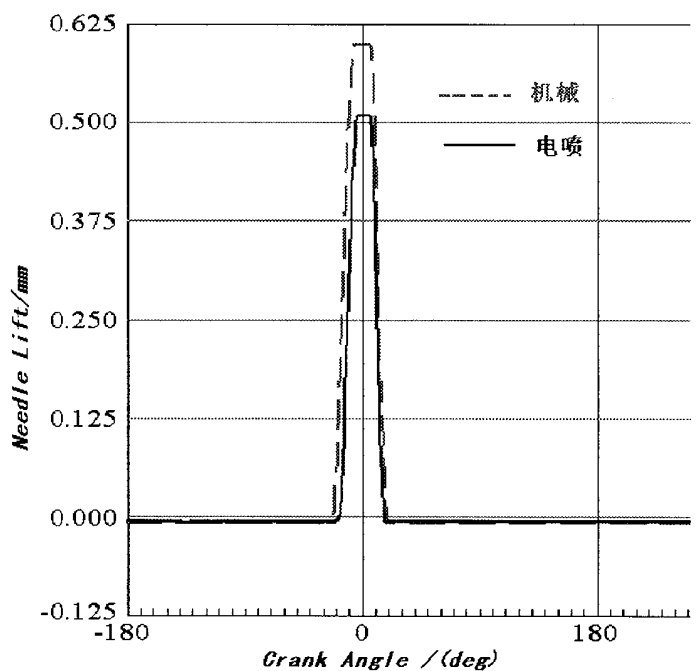

Fig. 5 Needle lift curve 


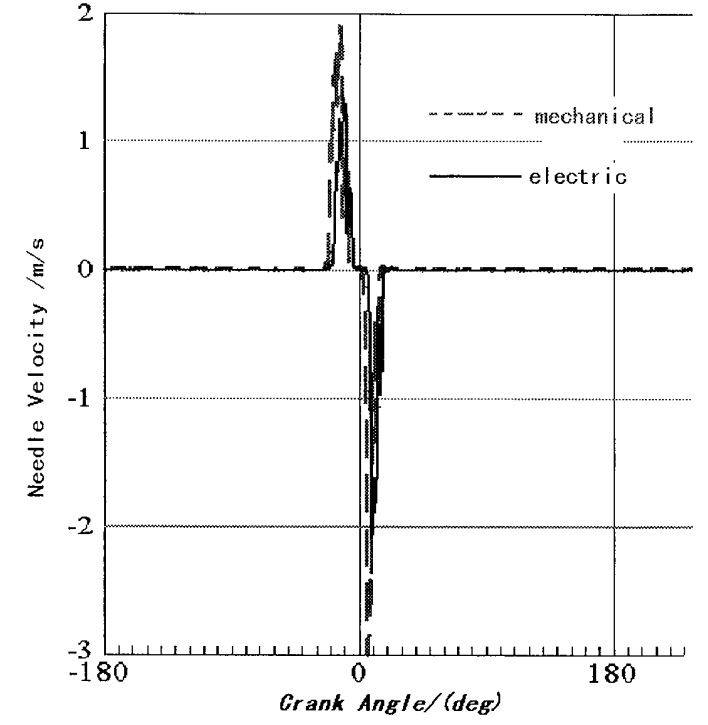

Fig.6 Needle velocity curve

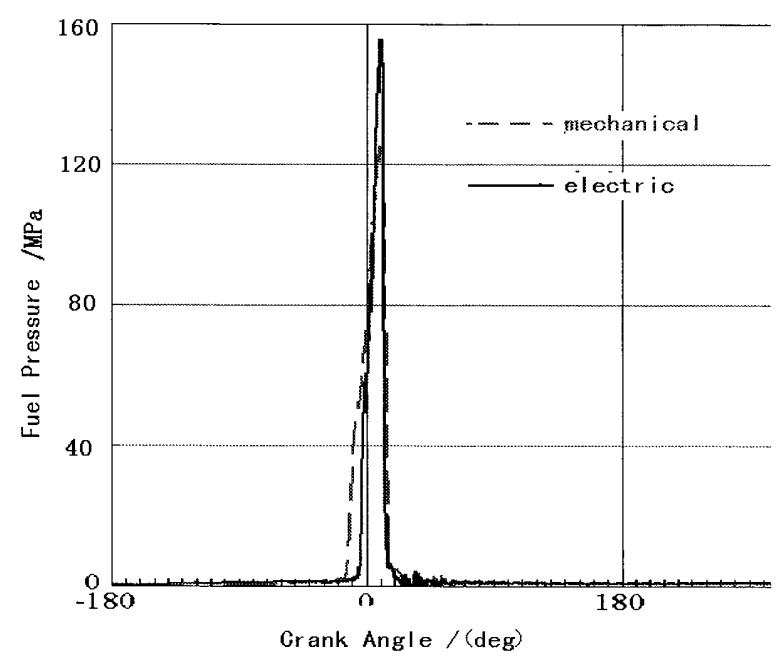

Fig.7 Feed pressure curve

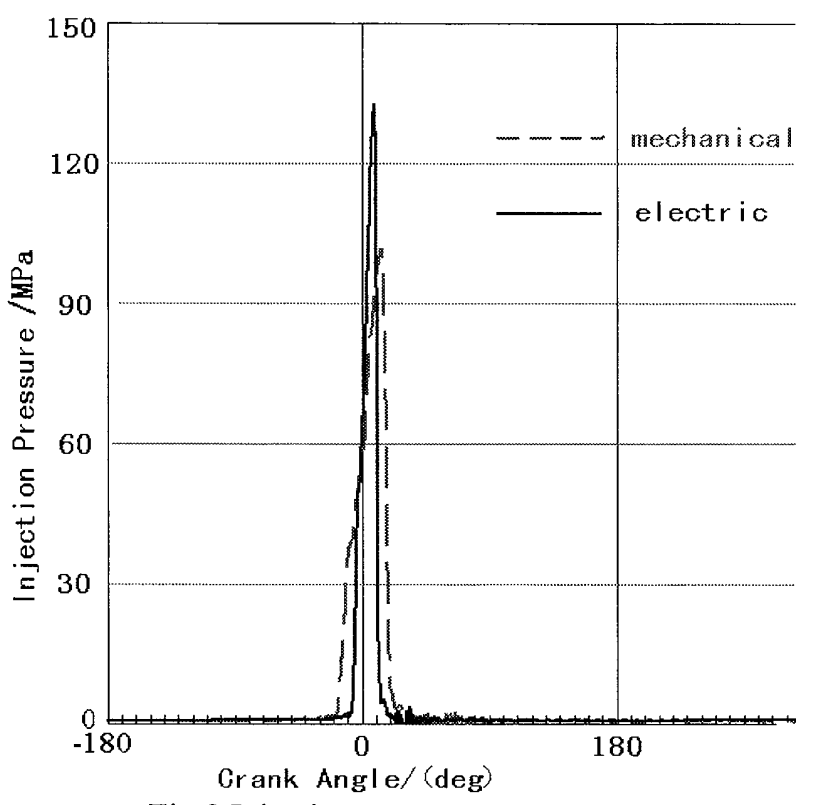

Fig.8 Injection pressure curve

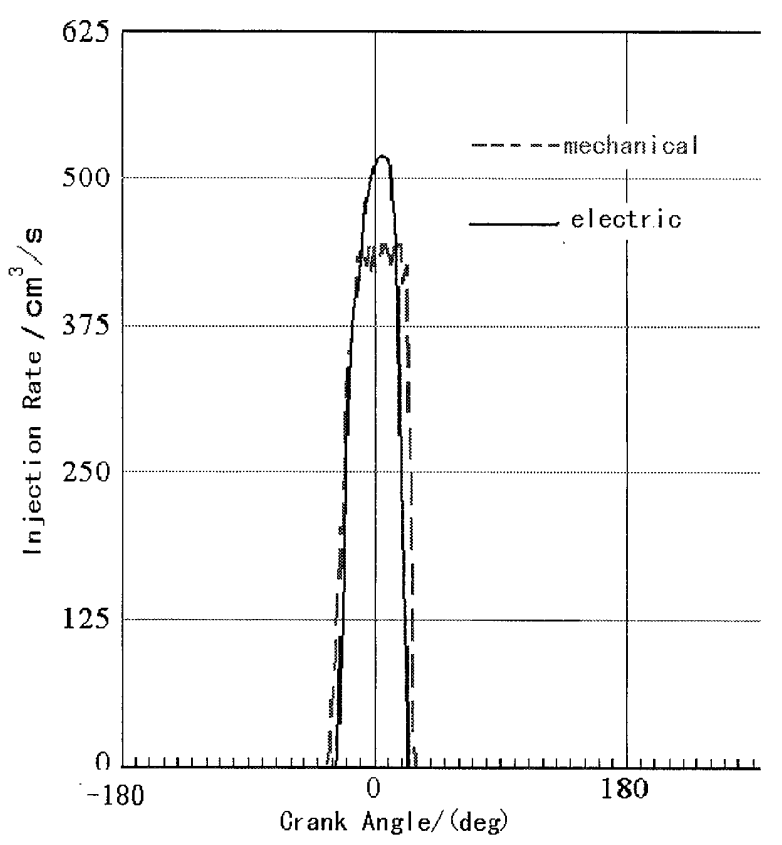

Fig.9 Injection rate curve

Figure 3 is the Experiment result of the mechanical 16V280, Figure 4 to Figure9 is the result of the Simulation. Its solid line represents the electrically controlled simulation result, dashed line for the mechanical simulation result. In the simulation the TDCF is $0^{\circ}$ crankangle. Figure 4 obviously shows the solenoid valve closure angle is $-17^{\circ}$ crank angle and starts to open at $10^{\circ}$ crank angle, so the feeding timing is $17^{\circ}$ crank angle and the feeding duration is for $27^{\circ}$. In Figure 5 the needle lift curve is basically trapezoidal shape, after $-15^{\circ}$ crank angle the lift stabilize in $0.5 \mathrm{~mm}$ place and starts to fall at $13^{\circ}$ crank angle. Comparing to the mechanical opening angle, it slightly lag. Postponeding the injectiong timing has the advantage to reducing the NOx emission. The maximum Velocity of movement of electricity injection' needle is $2.1 \mathrm{~m} / \mathrm{s}$, but requests this speed not to surpass $2.3 \mathrm{~m} / \mathrm{s}$ generally, obviously however Figure 6 electricity injection' needle velocity of movement is quite reasonable. Replacing the long stem needle, the Electrically controlled injector adopt the short stem needle which is approximate in U. It causes the needle lift to reduce $0.5 \mathrm{~mm}$ from $0.6 \mathrm{~mm}$, not only causes the needle velocity of movement to slow down obviously, thus is advantageous to the needle organization motion parts force of inertia reduction, to reducing the needle plays certain role to the place surface impact stress, moreover to reducing needle 's bouncing phenomenon, and avoids the drop oil and fuel oil returns to flee the positive sense.

From Figure 8 and Figure 7, we can know that comparing the mechanical injection system, the Electrically controlled system's injection pressure has the remarkable enhancement. The Electronic highest injection pressure achieves $135 \mathrm{MPa}$, compared to mechanical type has been higher than $35 \mathrm{MPa}$, has achieved the highest injection pressure design requirements. High injection pressure auses an average atomization grain of diameter to reduce, Promoting the oil atomization, and forms the even mixture air with the air in cylinder. Elevation of injection pressure causes the atomization to tie local region's oil gas 
equivalence ratio to reduce, but in the energy high local region, the air can compared to introduce the fog to tie actively. Therefore, partial the thick mixture ratio example has reduced, favors in the exhaust black smoke reduction.

The injection rate curve has three kinds roughly: rectangle curve, " $\Delta$ " (delta) and "boots" curve. The "boots" injection is one kind compared to ideal blow curve. The electrically controlled injection transforms by mechanical moment injection as "boots" injection. This injection can realize the first slow, anxious fuel injection. In the initial period of injection, the injection quantity and rate reduce, this may reduce "delay period", reduces pressure lifting rate, thus reduces NOx the production quantity and Enhances the engine stability, is good to the noise reduction.

In the injection intermediate stage, spraying the oil by high blow speed into the cylinder can makes the oil to deflagrate and to maintain the high combustion temperature, thus reduces the fuel oil consumption and carbon smoke emission. The injection later period is the injection pressure reduces time, because the fuel atomization condition is bad, will cause smoke emission increase, therefore should reduce the injection time as far as possible and stops the oil should be simply rapid. By Figure 9, electrically controlled system stops the oil more rapid than the traditional mechanical type moreover the injection duration reduces correspondingly, this can create advantage for reducing combustion and exothermic duration, thus it can reduce the after burns and causes the combustion and exothermic to carry on approaching top dead center's sector to enhance thermal efficiency and efficiency.

Therefore, before when the $16 \mathrm{~V} 280 \mathrm{ZJ}$ diesel engine electronic control injection system's feed angle of advance is TDCF $17^{\circ}$, the crank corner, the needle lift, the injection pressure and blow speed curve is more ideal. This was after considering the efficient and an emission factor good trade-off decision.

\section{CONCLUSION}

At present, the electronic fuel injection technology on gasoline engine and low power diesel engine obtained the widespread application. Along with the high efficiency high-speed solenoid valve and so on gradual breakthrough of the key technologies, application of the electronic control fuel injection system will also obtain the vigorous promotion on locomotive diesel engine.

Draws the following conclusion through the electrically controlled simulation research of system on 16V280ZJ diesel engine.

(1) Because the electronically controlled pump-pipe -injector fuel injection system in the structure is very similar to the mechanical injection system, through the suitable transformation, the mechanical fuel system may alter to the electronic Control system and saved the cost.

(2) The electronic Control system enhances the injection pressure and rate, obtaining low fuel oil consumption. also it Dramatically improves locomotive diesel engine's efficiency.

(3) When the diesel engine has the heavy accident, the control system can turn on the solenoid valve to shut off fuel oil channel to cause the engine fast to stop working. Enhancing engine's operational reliability, is advantageous moves stably in the diesel engine.

(4) This article used the GT simulation software to establish the locomotive electrically controlled diesel engine injection system's computation model, and adopted the experiment to confirm the computation model accuracy. It had indicated in the modern diesel engine design process, the good computation software has been possible to simulate the diesel engine actual work process quite precisely. This may provide the correct instruction for the designer, saves a big experimental and revision design expense, improves the design quality, dramatically sped up the design schedule.

Because establishment of the injection pressure still depends upon the oil pump cam to promote the plunger production, the pump-pipe -injector fuel injection system also has some inherent defects. Along with the breakthrough of high pressure common rail technique, these flaws will be overcomed one by one. Believes the near future, locomotive electrically controlled diesel oil opportunity enters a prosperous period of development.

\section{REFERENCES}

1. Zhou Longbao, Internal combustion engine study $[\mathrm{M}]$, Beijing: Mechanical industry publishing house, (2005)

2. Qishuyan Locomotive plant. 16V280 diesel engine [M], Beijing: Chinese Railroad Publishing house, (2004).

3. Li Minghai, Liu Gu, 16V280ZJ diesel engine fuel system reliability studies [J], Internal Combustion Engine Project, 2 (2002).

4. Wang Shangyong, Yang Qing, Diesel engine electronic control technology [M], Beijing: Mechanical industry publishing house, (2005).

5. Sun Jianqing, The diesel engine electrically controlled pump nose fuel injection system simulation studies [D], Harbin: Harbin Engineering University, (2006).

please contact

Prof. Li Minghai

Dalian Jiaotong University, LiaoNing Dalian, China

Phone \&Fax +86(411)84109290

E-mail dlminghai@vip.sina.com 